\title{
Deep vein thrombosis related to environment (Review)
}

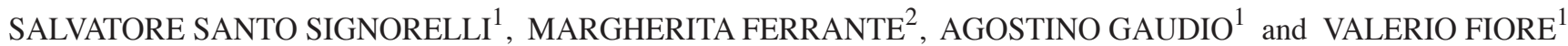 \\ Departments of ${ }^{1}$ Clinical and Experimental Medicine and ${ }^{2}$ Medical, Surgical Sciences and \\ Advanced Technologies 'G.F. Ingrassia', University of Catania, I-95123 Catania, Italy
}

Received December 30, 2016; Accepted February 13, 2017

DOI: $10.3892 / \mathrm{mmr} .2017 .6395$

\begin{abstract}
The first-time venous thromboembolism (VTE) is less frequent than other thrombotic events, however, both the pulmonary embolism (PE) and the deep vein thrombosis (DVT) show a frequent morbidity. Many factors play as risk situations in determining VTE, and the air exposure to the fine and ultrafine particulate matter (PM) as $\mathrm{PM}_{10}, \mathrm{PM}_{2.5}$, $\mathrm{PM}_{0.1}$ is considered. Epidemiological studies have supported this association although both the effective burden of the association and the mechanisms are to date unclear. The PM concentrations and the exposure time are notable as emerging factors. Interestingly, the seasonal climate variations resulted as effective risk factor for appearance of VTE or DVT. There is a need to ameliorate the environment by reducing the air pollution at global scale.
\end{abstract}

\section{Contents}

1. Introduction

2. Pathophysiology

3. Air exposure and venous thrombotic disease

4. How do we explain the confounding results among the association?

5. Mechanisms to link inflammation with the PM exposure, and with VTE epidemiology

6. Effect of climate

7. Conclusions

\section{Introduction}

The incidence of first-time venous thromboembolism (VTE) affects a substantial number of subjects, in fact it ranges between 62 and 143/100,000/year although it seems to differ ranging

Correspondence to: Professor Salvatore Santo Signorelli, Department of Clinical and Experimental Medicine, University of Catania, Via Santa Sofia 78, I-95123 Catania, Italy

E-mail: ssignore@unict.it

Key words: deep vein thrombosis, particulate matter, climate, coagulation between 19 and 50/100,000 persons/years $(1,2)$. Although the VTE incidence is lower than the arterial thromboses (coronary and carotid arteries) both the pulmonary embolism (PE) and the deep vein thrombosis (DVT) show morbidity cases. More situations are risk factors for the VTE in individuals. A number of factors are able to promote the risk for VTE, and many epidemiological and interventional studies have focused on several favourable situations (3-7). The conclusive statements of these have produced the scores to know the possible risk for VTE and also to forward the early and useful approach to diagnose and to manage VTE.

\section{Pathophysiology}

The low rate of shear and the raised activity of the coagulative cascade play a role for thrombotic disease in the venous circle. The low rate of shear and the raised activity of the coagulative cascade play a role for thrombotic disease in the venous circle. Such effects may comprise the occurrence of immunologic reaction including the hypersensitivity that can be modulate with different immunosuppressive treatments $(8,9)$. The coagulative factor VII (FVII) and the tissue factor (TF) represent the complex able to move other coagulative components inducing the thrombin generation $(\mathrm{T})$. The $\mathrm{T}$ seems to be the key enzyme leading to convert the monomers of fibrinogen $(\mathrm{F})$ to polimers of fibrin (Fib). In this way amplifying the coagulative cascade through the activation of other coagulative factors such as V (FV), VIII (FVII) and X (FX) factors.

\section{Air exposure and venous thrombotic disease}

In 2004 the American Heart Association recognized the deleterious effect caused by exposure to air components particularly by the fine particulate matter (PM) on cardiovascular system. The air pollutants especially the particles sized $<10 \mathrm{~mm}$ diameter $\left(\mathrm{PM}_{10}\right)$ have been associated with an increased risk for cardiovascular events (i.e., myocardial infarction (MI), stroke, arrhythmia and heart failure) (10). Most recently, based on the negative effect played by the fine and the ultrafine air pollutants on coagulative balance, several studies have postulated the possible association between exposure to the air pollutants with the risk and/or appearance of VTE. Epidemiological studies have supported this association although to date both the effective burden of the epidemiological association and the possible mechanisms are unclear on the effect in promoting the pathologic link. 
The size of pollutants is closely related to the pathogenic activities so far the particulate air pollutants are divided into several groups. The two main are the coarse component with aerodynamic diameter between 2.5 and $10 \mathrm{~mm}\left(\mathrm{PM}_{10-2.5}\right)$, and the finest component with diameter $<2.5 \mathrm{~mm}\left(\mathrm{PM}_{2.5}\right)$. These air components are different regarding their sources and composition. Indeed, while $\mathrm{PM}_{2.5}$ particles result mainly from combustion of fossil fuels from a variety of activities (e.g., traffic and industry), the $\mathrm{PM}_{10-2.5}$ particles are associated with non-combustion surface or fugitive releases by a variety of human (e.g., agriculture) and natural (e.g., erosion) activities. The $\mathrm{PM}_{10-2.5}$ particles are found preferentially in the upper and larger airways of the lung, while the $\mathrm{PM}_{2.5}$ particles are found in the smallest airways and in the pulmonary alveoli. The finest particles (ultrafine particles sized $0.1 \mathrm{~mm}$ ) can spread even into the systemic circulation throughout the alveolar-capillary wall. All these particles have shown the capability of disarranging the coagulative balance, in fact the PMs have been associated to changes in global hemostastic human capability and also the exposure (short and prolonged) induces a dramatic hypercoagulative situation. Epidemiological studies have demonstrated that the PM exposure shortened the prothrombin time (PT) and on the other hand the PM increased the plasma level of Fib. These haemostatic disturbances were associated to the DVT appearance. Unfortunately, studies have not supported the positive association between the inhaled pollutants and the DVT (11-13). To explain the confounding results we can consider the role played by the time of the PM exposure. It was found that prolonged time of exposure to PM over one year is crucial in inducing risk of DVT. Differently, the short time of PM exposure (one week maximum) did not result in positive correlation to the DVT. In this regard, experimental study demonstrated that the direct short time intra-tracheal instillation of the pollutants raised the clot in the arterial bed but not in the venous circulation (14). However, other experiments have found that high-doses (100 mg or more) of PM induced in short time such hypercoagulative effects (15). It increased the Fib level and conversely decreased the level of the $\mathrm{C}$ and $\mathrm{S}$ antithrombotic proteins. Interestingly, it has been demonstrated that also a dose of $10 \mu \mathrm{g}$ of $\mathrm{PM}_{10}$ may induce effects on coagulative balance. When a low-dose of pollutant was directly instilled into the tracheal space in animals, it caused several procoagulative effects. In fact a shortened PT was found and conversely an activated PT (aPTT) and the platelet count, the V, VII and X coagulative factors and the Fib were found increased (11).

\section{How do we explain the confounding results among the association?}

It is notable that more experiences have demonstrated that the PM exposure affects the pro-coagulative inflammatory pathway. Experimental findings found the absence of the PM prothrombotic pathway in knockout IL-6 mouse, and this result recognized the association between PM exposure and inflammation as possible major strength in inducing the relationship between the air pollutants and the venous thrombotic diseases (15). This is a relevant issue to emphaticize the role of the inflammatory markers in explaining the association between fine and ultrafine pollutants in VTE. In this context, we must focus on the role played by such minor inflammatory markers as the Fib. The Fib is an acute phase protein that is usually upregulated during inflammation. It is also a possible coagulative-inflammatory marker of prothrombotic activation. However, it plays a minor role in clot and it cannot explain alone the relationship between PM exposure and VTE. Indeed such studies have shown the negative effect of the short time direct PM exposure in causing activation of coagulative cascade through release of inflammatory markers (16-21).

\section{Mechanisms to link inflammation with the PM exposure, and with VTE epidemiology}

In contrast to the unclear knowledge concerning the mechanisms able to explain the association between air pollutants and venous thrombosis, an interesting and potential role seems to exist in the circulating number of the so-called microvescicles (or microparticles that are sized $<1 \mu \mathrm{m}$ derived from stimulated or apoptotic cells. High number of these microvescicles has been found as circulating both in subjects chronically exposed to high level of air pollutants and in patients affected by VTE. These microvescicles negatively charged the phospholipids and TF, consequently, their surfaces attract more procoagulative factors. Results from studies have highlighted the number and/or procaogaulative capability of these microvesciscles found in patients with VTE $(22,23)$. It was shown that long (acute, subacute, chronic) duration of exposure to the pollutants caused different and increased number of the circulating microvescicles. Current PM (short time) levels were associated with the lower numbers of circulating microvesicles and with the decreased measurements of the inflammatory parameters. The chronic PM exposure causes procoagulant tendency as shown by the thrombin generation and by several markers of surface expression of negatively charged phospholipids (24-26). Upregulation of procoagulant microvesicles could explain the pathophysiological mechanism underlying the found association between chronic PM exposure and high number of microvesicles and their procoagulant activity. Chronic PM exposure window seems to determine such procoagulant changes as the higher microvesicle numbers have shown. High number of microvescicles both blood-platelet derived and red blood cell-derived added to the increased microvesicular Annexin $\mathrm{V}$ binding reflect the surface expression of negatively charged phospholipids (mainly phosphatidylserine) (26-29). The role of inflammation and specific immunity is close debated among several situation also focusing on the thrombotic process. Although, the link between environment variations with VTE is less established than to arterial thrombotic events, however, the air pollutants negatively act on several targets (leukocyte, platelets, coagulative factors, inflammatory markers and endothelial markers). These cells and factors play roles in pathophysiology both of venous (i.e., DVT) and arterial thrombotic diseases (28).

\section{Effect of climate}

A large body of data postulated a seasonal effect on the frequency and/or incidence of VTE. In this regard, such 
studies have highlighted on possible reasons, and firstly the haemostatic unbalance was considered. The effects caused on packed cell volume, on platelet count and on their volume have been demonstrated (30). Moreover, other factor to explain the seasonal variation of VTE frequency seems to be a reduced physical activity during the winter. The limited physical activity acts particularly on subjects (patients) suffering from chronic diseases (i.e., chronic pulmonary insufficiency, heart failure and malignancies). It also particularly acts on older subjects. It is known that all the aforementioned situations are usually considered as risk factors for VTE appearance. Furthermore, we must take into account that the winter low temperature raises the urban motor traffic, and as consequence, it increases the level of air pollutants (25,31-34). In turn, because the deleterious effect is known of inhaled pollutants on haemostatic balance we can explain also the seasonal variations of the DVT during the cold time compared to other seasons. Research performed in many countries and regions have stated the association between epidemiology of the DVT with the cold climate. Interestingly, a positive trend for the DVT appearance was found by Manfredini et al (35) in subset of hospitalized patients for DVT that concomitantly were affected by pulmonary diseases. The chronobiological trend has been demonstrated most recently by the multicenter study for a thromboembolism registry (MASTER) (36). These results show that more VTE events appeared during the autumn compared to lower rate of VTE events in the summer time. The seasonal variation affects the patients with coagulative deficiencies (i.e., deficiency of the $\mathrm{C}$ and $\mathrm{S}$ anticoagulant proteins). As we know the subjects are more prone to thromboembolism. The frequency of the DVT (and/or VTE) in these subjects significantly increases in the autumn (November) (37). Results from the Korean registry (38) has shown a raised frequency in DVT diagnoses both in autumn and winter compared to the hot seasons. To date there is still an active debate among the effective reasons to associate the climate variations and the environment changes with the frequency of the DVT. However, we hypothesized that cold climate negatively acts both on the coagulative balance and on the peripheral vasoconstriction, and it increases the vasoconstrictive tone of artery-venous shunt (39). All these situations are risk factors for thromboembolic events in venous circulation, and they may play a role in determining the frequency of VTE and DVT. On the contrary, the positive effect of the sun exposure on the VTE risk has been demonstrated (40). Reduction of the VTE risk up to $30 \%$ was found in subjects sunbathing both during winter and summer vacations. It is known that the exposure to ultraviolet light improves the vitamin D status (41). Furthermore, the anticoagulant capability of the 1,25 vitamin D is known as active metabolite of the vitamin D related to the upregulation of the thrombomodulin generation and conversely effect on the downregulation of the tissue factor $(42,43)$. In addition, an inverse correlation was found between the levels of the 25-OH vitamin D and the plasminogen activator inhibitor-1, and with the tissue-type plasminogen activator antigen (44). These findings support the etiological effect of climate on the emerging risk and on the clinical appearance of venous thrombotic disease of lower limbs as venous diseases potentially relate to seasonal variations.

\section{Conclusions}

In conclusion, there is a large body of research focused on pathophysiologic and on epidemiologic questions, and these have provided consistent evidence on the dangerous effects on the cardiovascular system originated from current and prolonged inhalation of air pollutants. Particulate matters $\left(\mathrm{PM}_{10}, \mathrm{PM}_{2.5}\right.$, ultrafine $\left.\mathrm{PM}\right)$ play a crucial role both in determining procoagulant disorders and in promoting an inflammatory pathway. All these situations play a pathogenetic role on thrombotic diseases and particularly on VTE. However, the link between environment variations with VTE is less established than to arterial thrombotic events, however, the air pollutants negatively act on several targets (leukocyte, platelets, coagulative factors, inflammatory markers and endothelial markers) which play crucial roles in pathophysiology of the VTE and DVT. We agree with the conclusive remarks given by Emmerechts et al (45) who considered the exposure to air pollutants as the highest risk factors for thrombotic events. Therefore, there is a need to reduce such exposure both at individual and global level.

\section{References}

1. Cohen AT, Agnelli G, Anderson FA, Arcelus JI, Bergqvist D, Brecht JG, Greer IA, Heit JA, Hutchinson JL, Kakkar AK, et al; VTE Impact Assessment Group in Europe (VITAE): Venous thromboembolism (VTE) in Europe. The number of VTE events and associated morbidity and mortality. Thromb Haemost 98: 756-764, 2007.

2. Heit JA, Melton LJ III, Lohse CM, Petterson TM, Silverstein MD, Mohr DN and O'Fallon WM: Incidence of venous thromboembolism in hospitalized patients vs community residents. Mayo Clin Proc 76: 1102-1110, 2001.

3. Wells PS, Hirsh J, Anderson DR, Lensing AW, Foster G, Kearon C, Weitz J, D'Ovidio R, Cogo A, Prandoni P, et al: Accuracy of clinical assessment of deep-vein thrombosis. Lancet 345: 1326-1330, 1995.

4. Prandoni P, Polistena P, Bernardi E, Cogo A, Casara D, Verlato F, Angelini F, Simioni P, Signorini GP, Benedetti L, et al: Upper-extremity deep vein thrombosis. Risk factors, diagnosis, and complications. Arch Intern Med 157: 57-62, 1997.

5. Clagett GP and Reisch JS: Prevention of venous thromboembolism in general surgical patients. Results of meta-analysis. Ann Surg 208: 227-240, 1988.

6. Kearon C, Julian JA, Newman TE and Ginsberg JS: Noninvasive diagnosis of deep venous thrombosis. McMaster Diagnostic Imaging Practice Guidelines Initiative. Ann Intern Med 128: 663-677, 1998.

7. Barbar S, Noventa F, Rossetto V, Ferrari A, Brandolin B, Perlati M, De Bon E, Tormene D, Pagnan A and Prandoni P: A risk assessment model for the identification of hospitalized medical patients at risk for venous thromboembolism: the Padua prediction score. J Thromb Haemost 8: 2450-2457, 2010.

8. Donia M, Mangano K, Quattrocchi C, Fagone P, Signorelli S, Magro G, Sfacteria A, Bendtzen K and Nicoletti F: Specific and strain-independent effects of dexamethasone in the prevention and treatment of experimental autoimmune encephalomyelitis in rodents. Scand J Immunol 72: 396-407, 2010.

9. Mangano K, Nicoletti A, Patti F, Donia M, Malaguarnera L, Signorelli S, Magro G, Muzio V, Greco B, Zaratin P, et al: Variable effects of cyclophosphamide in rodent models of experimental allergic encephalomyelitis. Clin Exp Immunol 159: 159-168, 2010.

10. Brook RD, Franklin B, Cascio W, Hong Y, Howard G, Lipsett M, Luepker R, Mittleman M, Samet J, Smith SC Jr, et al; Expert Panel on Population and Prevention Science of the American Heart Association: Air pollution and cardiovascular disease: a statement for healthcare professionals from the Expert Panel on Population and Prevention Science of the American Heart Association. Circulation 109: 2655-2671, 2004. 
11. Gilmour PS, Morrison ER, Vickers MA, Ford I, Ludlam CA, Greaves M, Donaldson K and MacNee W: The procoagulant potential of environmental particles $\left(\mathrm{PM}_{10}\right)$. Occup Environ Med 62: 164-171, 2005.

12. Pekkanen J, Brunner EJ, Anderson HR, Tiittanen P and Atkinson RW: Daily concentrations of air pollution and plasma fibrinogen in London. Occup Environ Med 57: 818-822, 2000.

13. Baccarelli A, Zanobetti A, Martinelli I, Grillo P, Hou L, Giacomini S, Bonzini M, Lanzani G, Mannucci PM Bertazzi PA, et al: Effects of exposure to air pollution on blood coagulation. J Thromb Haemost 5: 252-260, 2007.

14. Emmerechts J, Alfaro-Moreno E, Vanaudenaerde BM, Nemery B and Hoylaerts MF: Short-term exposure to particulate matter induces arterial but not venous thrombosis in healthy mice. $\mathrm{J}$ Thromb Haemost 8: 2651-2661, 2010.

15. Mutlu GMD, Green D, Bellmeyer A, Baker CM, Burgess Z, Rajamannan N, Christman JW, Foiles N, Kamp DW, Ghio AJ, et al: Ambient particulate matter accelerates coagulation via an IL-6-dependent pathway. J Clin Invest 117: 2952-2961, 2007

16. Beckett WS, Chalupa DF, Pauly-Brown A, Speers DM, Stewart JC, Frampton MW, Utell MJ, Huang LS, Cox C, Zareba W, et al: Comparing inhaled ultrafine versus fine zinc oxide particles in healthy adults: a human inhalation study. Am J Respir Crit Care Med 171: 1129-1135, 2005.

17. Barregard L, Sällsten G, Gustafson P, Andersson L, Johansson L, Basu S and Stigendal L: Experimental exposure to wood-smoke particles in healthy humans: effects on markers of inflammation, coagulation, and lipid peroxidation. Inhal Toxicol 18 $845-853,2006$

18. Rückerl R, Ibald-Mulli A, Koenig W, Schneider A, Woelke G, Cyrys J, Heinrich J, Marder V, Frampton M, Wichmann HE, et al: Air pollution and markers of inflammation and coagulation in patients with coronary heart disease. Am J Respir Crit Care Med 173: 432-441, 2006

19. Rudez G, Janssen NA, Kilinc E, Leebeek FW, GerlofsNijland ME, Spronk HM, ten Cate H, Cassee FR and de Maat MP: Effects of ambient air pollution on hemostasis and inflammation. Environ Health Perspect 117: 995-1001, 2009.

20. Thompson AM, Zanobetti A, Silverman F, Schwartz J, Coull B Urch B, Speck M, Brook JR, Manno M and Gold DR: Baseline repeated measures from controlled human exposure studies: associations between ambient air pollution exposure and the systemic inflammatory biomarkers IL-6 and fibrinogen. Environ Health Perspect 118: 120-124, 2010.

21. Myers DD, Hawley AE, Farris DM, Wrobleski SK, Thanaporn P, Schaub RG, Wagner DD, Kumar A and Wakefield TW: P-selectin and leukocyte microparticles are associated with venous thrombogenesis. J Vasc Surg 38: 1075-1089, 2003.

22. Bucciarelli P, Martinelli I, Artoni A, Passamonti SM, Previtali E, Merati G, Tripodi A and Mannucci PM: Circulating microparticles and risk of venous thromboembolism. Thromb Res 129 591-597, 2012

23. Ye R, Ye C, Huang Y, Liu L and Wang S: Circulating tissue factor positive microparticles in patients with acute recurrent deep venous thrombosis. Thromb Res 130: 253-258, 2012.

24. O'Neill MS, Veves A, Zanobetti A, Sarnat JA, Gold DR, Economides PA, Horton ES and Schwartz J: Diabetes enhances vulnerability to particulate air pollution-associated impairment in vascular reactivity and endothelial function. Circulation 111 2913-2920, 2005.

25. Baccarelli A, Martinelli I, Zanobetti A, Grillo P, Hou LF, Bertazzi PA, Mannucci PM and Schwartz J: Exposure to particulate air pollution and risk of deep vein thrombosis. Arch Intern Med 168: 920-927, 2008

26. Emmerechts J, Jacobs L, Van Kerckhoven S, Loyen S, Mathieu C, Fierens F, Nemery B, Nawrot TS and Hoylaerts MF: Air pollution-associated procoagulant changes: the role of circulating microvesicles. J Thromb Haemost 10: 96-106, 2012.

27. Morel O, Toti F, Hugel B, Bakouboula B, Camoin-Jau L, Dignat-George F and Freyssinet JM: Procoagulant microparticles: disrupting the vascular homeostasis equation? Arterioscler Thromb Vasc Biol 26: 2594-2604, 2006.
28. Signorelli SS, Fatuzzo P, Rapisarda F, Neri S, Ferrante M, Oliveri Conti G, Fallico R, Di Pino L, Pennisi G, Celotta G, et al: A randomised, controlled clinical trial evaluating changes in therapeutic efficacy and oxidative parameters after treatment with propionyl L-carnitine in patients with peripheral arterial disease requiring haemodialysis. Drugs Aging 23: 263-270, 2006.

29. Chirinos JA, Heresi GA, Velasquez H, Jy W, Jimenez JJ, Ahn E, Horstman LL, Soriano AO, Zambrano JP and Ahn YS: Elevation of endothelial microparticles, platelets, and leukocyte activation in patients with venous thromboembolism. J Am Coll Cardiol 45: 1467-1471, 2005.

30. Keatinge WR, Coleshaw SR, Cotter F, Mattock M, Murphy M and Chelliah R: Increases in platelet and red cell counts, blood viscosity, and arterial pressure during mild surface cooling: factors in mortality from coronary and cerebral thrombosis in winter. Br Med J (Clin Res Ed) 289: 1405-1408, 1984.

31. Ghio AJ, Hall A, Bassett MA, Cascio WE and Devlin RB: Exposure to concentrated ambient air particles alters hematologic indices in humans. Inhal Toxicol 15: 1465-1478, 2003.

32. Baccarelli A, Martinelli I, Pegoraro V, Melly S, Grillo P, Zanobetti A, Hou L, Bertazzi PA, Mannucci PM and Schwartz J: Living near major traffic roads and risk of deep vein thrombosis. Circulation 119: 3118-3124, 2009.

33. Dales RE, Cakmak S and Vidal CB: Air pollution and hospitalization for venous thromboembolic disease in Chile. J Thromb Haemost 8: 669-674, 2010.

34. Martinelli N, Girelli D, Cigolini D, Sandri M, Ricci G, Rocca G and Olivieri O: Access rate to the emergency department for venous thromboembolism in relationship with coarse and fine particulate matter air pollution. PLoS One 7: e34831, 2012.

35. Manfredini R, Gallerani M, Boari B, Salmi R and Mehta RH: Seasonal variation in onset of pulmonary embolism is independent of patients' underlying risk comorbid conditions. Clin Appl Thromb Hemost 10: 39-43, 2004.

36. Manfredini R, Imberti D, Gallerani M, Verso M, Pistelli R, Ageno W and Agnelli G: Seasonal variation in the occurrence of venous thromboembolism: data from the MASTER registry. Clin Appl Thromb Hemost 15: 309-315, 2009.

37. Bilora F, Boccioletti V, Manfredini E, Petrobelli F, Tormene D, Simioni P and Girolami A: Seasonal variation in the incidence of deep vein thrombosis in patients with deficiency of protein $\mathrm{C}$ or protein S. Clin Appl Thromb Hemost 8: 231-237, 2002.

38. Jang MJ, Kim HJ, Bang SM, Lee JO, Yhim HY, Kim YK, Kim YK, Choi WI, Lee EY, Kim IH, et al: Seasonal variation in the occurrence of venous thromboembolism: a report from the Korean Venous Thromboembolism Working Party. Thromb Res 130: e199-e202, 2012.

39. Tayefeh F, Kurz A, Sessler DI, Lawson CA, Ikeda T and Marder D: Thermoregulatory vasodilation increases the venous partial pressure of oxygen. Anesth Analg 85: 657-662, 1997.

40. Lindqvist PG, Epstein E and Olsson H: Does an active sun exposure habit lower the risk of venous thrombotic events? A D-lightful hypothesis. J Thromb Haemost 7: 605-610, 2009.

41. Tangpricha V, Turner A, Spina C, Decastro S, Chen TC and Holick MF: Tanning is associated with optimal vitamin D status (serum 25-hydroxyvitamin D concentration) and higher bone mineral density. Am J Clin Nutr 80: 1645-1649, 2004.

42. Koyama T, Shibakura M, Ohsawa M, Kamiyama R and Hirosawa S: Anticoagulant effects of 1alpha,25-dihydroxyvitamin $\mathrm{D}_{3}$ on human myelogenous leukemia cells and monocytes. Blood 92: 160-167, 1998.

43. Sugden JA, Davies JI, Witham MD, Morris AD and Struthers AD: Vitamin D improves endothelial function in patients with type 2 diabetes mellitus and low vitamin D levels. Diabet Med 25: 320-325, 2008.

44. Scragg R, Sowers M and Bell C: Serum 25-hydroxyvitamin D, ethnicity, and blood pressure in the Third National Health and Nutrition Examination Survey. Am J Hypertens 20: 713-719, 2007.

45. Emmerechts J, Jacobs L and Hoylaerts F: Air pollution and cardiovascular disease. In: The Impact of Air Pollution on Health, Economy, Environment and Agricultural Sources. Khallaf MK (ed). InTech, Croatia, pp69-93, 2011. 